\title{
Problem of "False Positive" Conclusions in Genetic Epidemiology: Lessons From the Leukemia Cluster Near the Sellafield Nuclear Installation
}

\author{
James V. Neel \\ Department of Human Genetics, University of Michigan, Ann Arbor
}

\section{INTRODUCTION}

As you may imagine, I feel quite privileged to deliver the first presidential address to this Society. Although somewhat overlooked, in recent years the evolution of the field of genetic epidemiology has been just as dramatic as the evolution of other fields of genetic research, and the formation of this Society is a timely development. In 1954, W.J. Schull and I published a little textbook entitled Human Heredity. We took turns writing chapters for it. He, for instance, wrote those very nice chapters on statistical genetics. We felt there should be in the book a chapter on "Genetics and Epidemiology"- the first such chapter that I am aware of - and to me fell the challenge of writing that chapter. Anyone with any doubts as to how greatly the subject of genetic epidemiology has advanced in recent decades needs only go back and consider the comparative simplicity of what I wrote some 40 years ago.

Currently, genetic epidemiology presents two rather different faces. Face one is concerned with teasing the genetic component out of complex sets of family data. Here the objectives may vary from an attempt to link a marker gene to a phenotype, to an attempt to identify the existence of genetically caused variation in a phenotype by means of complex segregation analysis. Face two, on the other hand, is concerned

Received for publication November 11, 1993; accepted January 11, 1994.

Address reprint requests to Dr. James V. Neel, Department of Human Genetics, Box 0618, University of Michigan, 1500 E. Medical Center Drive, Ann Arbor, MI 48109-0618.

Presented as the Presidential Address to the International Genetic Epidemiology Society, New Orleans, LA, October 10, 1993.

Editor's Note: Dr. Neel was a paid expert for the defense in the trial described.

(C) 1994 Wiley-Liss, Inc. 
with the attempt to demonstrate that some rather unique experience of a population is reflected in one or more genetic endpoints.

No matter which of these approaches the genetic epidemiologist pursues, he is bedeviled by the problem of "false positives." There is no mystery as to how most of these false positives occur. It is not uncommon in much of what I will term "shotgun" genetic epidemiology for the investigator to explore the impact of as many as 20 different parental variables on perhaps 5 endpoints in their children. This matrix of 100 outcomes should, even in the absence of any real associations in the data, yield, on average, four outcomes significant at the $5 \%$ level of probability and one at the 1\% level. These "false positives," if the endpoint in question is one of societal significance - and these studies are presumably not undertaken for frivolous reasons-are often an apparent new cause for alarm. On the other hand, these "shotgun" studies, widely targeted though they may be, almost invariably have a rationale which leads to some expectation of one or more positive findings. Thus the practical issue is to determine which among the positive findings in a large-scale epidemiological study are meaningful and need to be pursued further and how best to proceed. In this connection, the term "false positive" is something of a misnomer. The data are not "false," but the conventions of statistical inference lead to some apparent outcomes which will not be supported by repeat studies.

In this presentation I shall describe what I consider to be the most major false alarm in type 2 genetic epidemiology in recent years, one that has consumed a great deal of public money and scientific time. My purpose is constructive: I hope by virtue of a thorough public airing of this situation, to help move the field of genetic epidemiology to a level of sophistication which will render the reoccurrence of such events improbable. Note that I do not aspire to render such events impossible, just less probable. The mind-set of the American people, and to a lesser extent, of other Western World peoples, is now so litigious that change will come slowly. The following quotation puts it quite succinctly.

Serious efforts to impose legal controls on the sources of societal risk date only from the mid-1960s. Most prominent in the public mind has been the creation of specialized federal agencies to directly regulate particular societal dangers-the Environmental Protection Agency, the Occupational Health and Safety Administration, the National Highway Traffic Safety Administration, and the Consumer Product Safety Commission as examples. But far more pervasive in scope and far more effective in impact than agency regulation has been the expansion of civil law to control risk. Since the late 1960s, our civil justice system has adopted the premise that civil damage awards enforcing liability rules and statutory rights can optimally regulate every source of societal risk. Building from this premise, our civil courts have become the most powerful institution of the modern state for regulating risk [Priest, 1990, p 207].

\section{CHILDHOOD LEUKEMIA IN WEST CUMBRIA}

The point of departure for this presentation is the epidemiological study conducted by Martin Gardner and associates on the occurrence of leukemia and lym- 
phoma among young people in West Cumbria, England [Gardner et al., 1987a,b, 1990a,b]. In 1983, Yorkshire television drew attention to an apparent excess of childhood leukemia in the vicinity of the Sellafield Nuclear Reprocessing Plant, which is located in West Cumbria, England. The presentation was sufficiently compelling that the English government commissioned a survey by an Independent Advisory Group, which confirmed that there was indeed an excess [Black, 1984; Gardner et al., 1987a,b], and Gardner and associates were then requested to undertake a study of associated risk factors, with particular reference to factors related to the plant. The subjects were 52 persons with leukemia, 22 with non-Hodgkin's lymphoma, and 23 with Hodgkin's disease, all with onset in people born in the area between 1950 and 1983 , with diagnosis under the age of 25 , and 1,001 controls matched for sex and age taken from the same birth registers as the cases [Gardner et al., 1990a,b]. Associations were sought with such factors as place of residence, viral infections, child's play habits, and parental occupational histories. As best I can estimate, some 80 possible associations were investigated. (This number in itself immediately raises the possibility of several "statistically significant" false positive associations simply on the basis of the number of tests performed.)

The principal positive finding was that relative risks for leukemia and nonHodgkin's lymphoma were higher in children born near Sellafield and in children of fathers employed at the plant. For example, the relative risk was 2.4 [95\% confidence interval (CI) of 1.0-5.7] for children of fathers employed at Sellafield at the time of their conception and 6.4 (CI 1.67-26.3) for children of fathers receiving a total preconceptual (external-badge-recorded) dose of ionizing radiation of more than $100 \mathrm{mSv}$ equivalents (but there were no exposures exceeding approximately $200 \mathrm{mSv}$ equivalents). The authors focused special attention on the village of Seascale, $3 \mathrm{~km}$ south of Sellafield, where a clustering of cases had been observed. Altogether 7 cases had been diagnosed in residents of the village under 25 years of age in the 29 years from 1955 to 1983,5 of which were in children under 10 years of age, when less than 1 case at these ages (actually, 0.5 cases) would have been expected at national rates. Four of the fathers of the affected children were employed in the Sellafield plant (expectation 0.6; relative risk 6.4), where they had received estimated total preconceptual (badge) doses of ionizing radiation ranging from 97 to $188 \mathrm{mSv}$ equivalents over a period of $6-13$ years. (For those more accustomed to the old units, $200 \mathrm{mSv}$ equivalents is $20 \mathrm{rem}$.) These doses were well within internationally accepted occupational guidelines. The authors concluded that "this result suggests an effect of ionizing radiation on fathers that may be leukemogenic in their offspring, though other, less likely, explanations are possible." That they believe this effect is genetic is indicated by their comparison of their findings with other, avowedly genetic studies, some to be mentioned later. The sensitivity of the human genome to the genetic effects of ionizing radiation implied by this interpretation is far, far in excess of current estimates, a statement I will document in detail in due course.

Understandably, the publication of these findings in the British Medical Journal in February of 1990 elicited a flurry of comments, some incredulous, some hailing a new major insight into radiation effects. The study of my associates and self on malignancies, including leukemia and lymphoma, in the $F_{1}$ of parents exposed to the explosions of the atomic bombs were then in press, not to appear until June 1990 [Yoshimoto et al., 1990], so when contacted by Science for comment, I could only 
express general disbelief and promise a more definitive response later. Needless to say, the world did not wait for our statement. A British law firm, Leigh, Day, and Company, advertised its willingness to file claims against the organization operating the facility, British Nuclear Fuel PIc (BNFL), and relatives of two of the children soon initiated action against BNFL, claiming damage for personal injuries and, in one of the two cases, death. A finding for the plaintiffs would challenge, worldwide, present permissible occupational exposures to ionizing radiation, as well as the validity of a major corpus of experimental data from the mouse, and the observational data from Japan on the children of atomic bomb survivors. Such a finding would also trigger a flood of similar legal actions. The stakes were high. So was the cost: The London Times has estimated (15 October 1992) that the resulting procedures, before the Royal High Courts of Justice of England, are expected "to be a record breaking legal action, costing up to $£ 10$ million" (US dollars $=16$ million). (The expenses of both plaintiffs and defendant will ultimately be met by the government.)

Concerning the reliability of the findings of Gardner and associates, there can be little doubt. A parallel study by McKinney and associates [1991] on parental occupations of children with leukemia in West Cumbria, North Humberside, and Gateshead, all areas in which high rates of childhood leukemia had previously been documented, confirmed the finding of the Gardner group in West Cumbria, not surprising in view of the overlap in subjects. McKinney et al. [1991] also reported significant associations of childhood leukemia with the preconceptional exposure of fathers to wood dust and benzene. The significance of these latter two findings must be viewed in light of the fact that by the authors' estimate, 480 comparisons were made. It is noteworthy that this study failed to confirm previously reported associations of childhood leukemia with parental exposure to pesticides, plastics, and paint and pigments--but these facts did not find their way into the abstract, let alone inspire a press release! Draper et al. [1993] several years later also confirmed the excess of leukemia in the Seascale area, and added additional data for 1984-1990, finding for the latter period that "the incidence of malignant disease, particularly lymphoid leukemia and non-Hodgkin's lymphomas in young people aged 0-24, in Seascale was higher than would be expected."

\section{LEGAL ACTION UNFOLDS}

The trial which resulted was conducted by a single judge in the Royal High Courts of Justice in London. I became involved in the trial, as a witness for the defense, in May of 1990. Ordinarily, I eschew legal involvements as carefully as I avoid contact with poison ivy, to which I am quite sensitive, but too much was at issue. I would like to share some of the developments of the past 3 years with you, because they provide an absolute textbook example of the complexities in mankind's efforts to define environmental/occupational risks. Everything I will discuss is either in the transcripts of the trial or has now appeared in the open scientific literature.

The trial was conducted according to long-established procedures for civil actions in England. The parties to the action agree on a sequence in which evidence will be introduced, in this instance, primarily the dosimetry, pathology, epidemiology, and genetics of the situation. Each side assembles an appropriate battery of consultants, who prepare Expert Reports. The Reports are exchanged by the two sides, and, 
based on the statements of the other side, a consultant may find himself preparing, as I did, a second, third, and even fourth Report. Comes the day when the consultant appears in court. First he is led through the substance of his reports by the counsel for the side he represents, then cross-examined, and then finishes in the hands of his counsel. It was all very orderly, but the fact that to make their case, counsel for the plaintiffs, guided in no small measure by the statements of their consultants, had to discredit the studies in Japan on the children of atomic bomb survivors with which I have been associated for some 47 years, did bring a bit of tension into the proceedings. In fact, I'm afraid I was unprepared for the level of innuendo, obfuscation, and distortion to which the plaintiffs' counsel resorted in attempting to cast doubt upon the validity of both the Japanese and murine data. Such tactics are a sad commentary on the adversarial ambience which characterizes society's efforts to deal with the type of complex scientific data with which it is increasingly confronted in environmental issues. With the legal profession willing to engage in such strategy to make a case, I am resigned to the fact that a balanced view of radiation (and other environmental) risks is not imminent.

Both the presiding judge and the barristers representing the two sides were generalists. By the time the case came to trial, the Expert Reports had grown to a formidable library, as did the testimony, which extended intermittently over a period of some 8 months. I was greatly impressed by the rapidity with which judge and barristers appeared to master the content and jargon of epidemiology and genetics, but at the same time concerned by the tremendous demands a highly technical hearing such as this places on a single judge, no matter how competent he is. Unfortunately, the plaintiffs' suit had the kind of surface plausibility that sometimes wins cases in a court of law. I would like now to run through the evidence that suggested to me (and other expert witnesses for the defendant) that the conclusions of Gardner and associates concerning the role of paternal exposure to ionizing radiation in the etiology of childhood leukemia in this setting were erroneous. Some of this evidence may be familiar to you, but I believe it will be useful to lay it all out in one place. An unusual feature of this trial was that relevant evidence continued to become available throughout the trial; I will introduce this "new" evidence last.

1. A comparison with the data on leukemia in the children of survivors of the atomic bombs. The genetic data of greatest relevance to the interpretation of the findings of the Gardner-group studies are those collected in the aftermath of the HiroshimaNagasaki bombings [reviewed in Neel and Schull, 1991]. Of special relevance are the studies on the occurrence of malignancies, including the leukemias, in the children of survivors and suitable control children [Yoshimoto et al., 1990, 1991]. In the course of these latter studies, an attempt was made to identify, on the basis of death certificates and the tumor registries maintained in Hiroshima and Nagasaki, all malignant tumors occurring during the period 1946-1985 in the cohort of children born in these two cities to parents who were within $2,000 \mathrm{~m}$ of the hypocenter at the time of the bombings and a suitably matched cohort of children whose parents were unexposed. The distribution of radiation doses in the combined cohorts, totaling 72,216 persons, is shown in Table I. The average conjoint gonadal acute dose of ionizing radiation for the exposed parents was $0.44 \mathrm{~Sv}$ equivalent. (Dose must be expressed in Sv equivalents because of the mixed gamma-neutron spectrum of ionizing radiation emitted by 


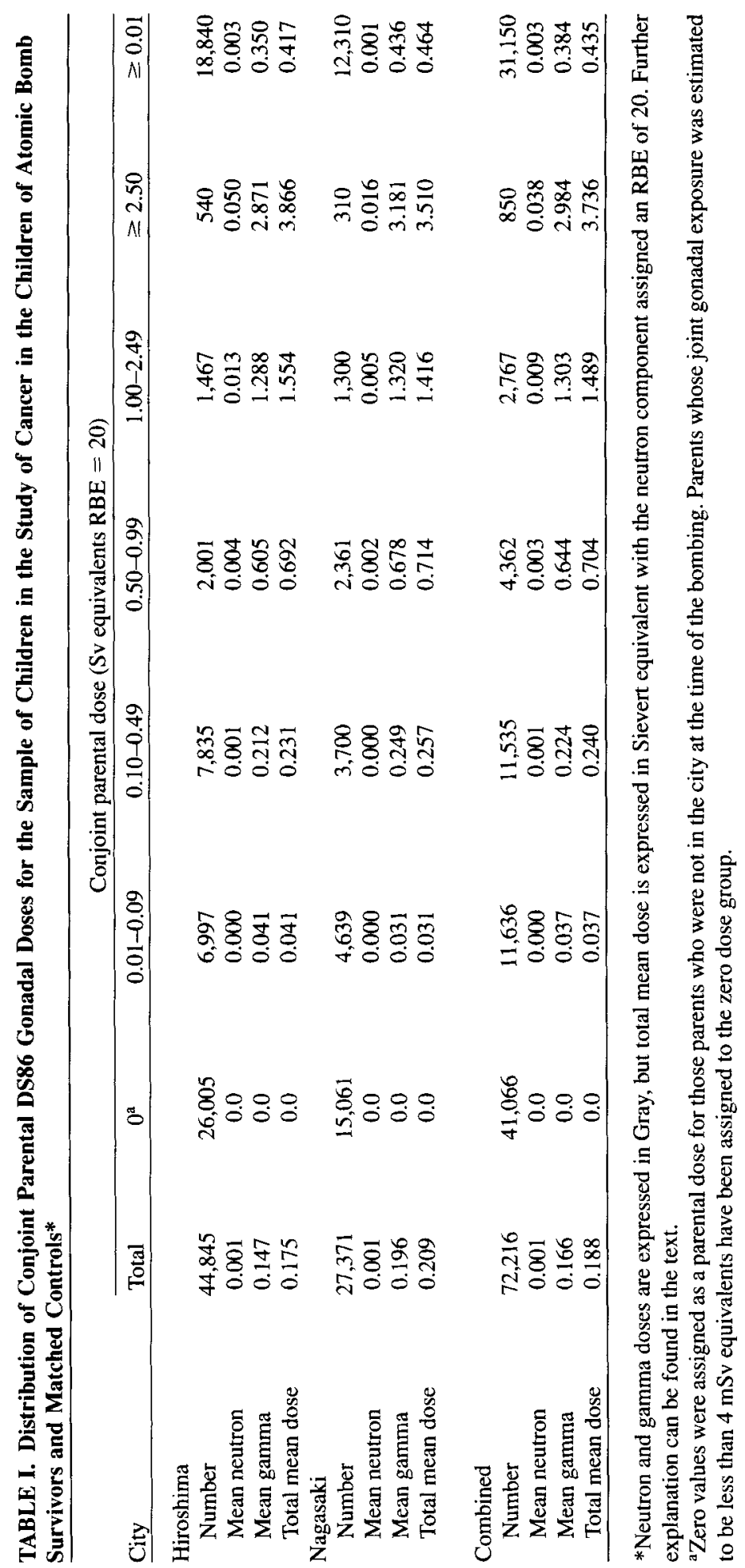


the atomic bombs.) The relationship between dose and incidence of malignancy was tested by a linear multiple regression model which included city, sex, and year of birth. There were 92 reports of malignant neoplasms in the combined cohorts. For analytic purposes, they were subdivided into three classes: leukemia, neoplasms in which genetic factors have been implicated (designated "heritable"), and other (Table II). For present purposes, we need only note the complete absence of any suggestion of an effect of parental exposure to ionizing radiation on the occurrence of leukemia.

In view of the lack of any suggestion of a radiation effect, we saw at the time no reason to carry the analysis further. (Philosophical point: I firmly believe that if main effects are negative, slicing and dicing the data with further analyses in the hopes of turning something up, if carried far enough, always yields a "statistically positive" finding which immediately becomes a source of embarrassment.) When, however, the data from Japan assumed such a prominent role in the trial, M.P. Little of the U.K. National Radiological Protection Board undertook major further analyses of our data [Little, 1990, 1991a,b, 1992, 1993]. It is the policy of the agency conducting followup studies in Japan on the late effects of the atomic bombs, the Radiation Effects Research Foundation, to make its data tapes available to qualified investigators. Obtaining his copy of our data tapes on malignancy in the $F_{1}$, Little first confirmed the validity of our analysis but then proceeded to pursue a number of additional points, as follows:

a. Little [1990] estimates not only that the two studies are statistically incompatible but that taken at face value the sensitivities with respect to leukemia implied by the Gardner study are 50-80 times greater than the results of the study in Japan. The implied difference between the two studies is even greater because whereas the Japanese doses were calculated gonadal exposures, the exposures in Sellafield were measured from film badges worn on the trunk (which overestimate gonadal exposures).

b. We had analyzed our findings with respect to conjoint parental exposures and in the absence of any suggestion of an effect, had not considered the parents separately. With the emphasis on paternal exposure in the Gardner-group study,

TABLE II. Regression Coefficients (Standard Errors in Parentheses) From a Linear Multiple Regression Analysis (Method of Least Squares) of the Incidence of Cancer Below the Age of 20 Years, by Conjoint Parental Dose (Sv Equivalents, RBE = 20), City, Sex, and Birth Years, Employing the Sample Defined in Table $\mathrm{I}^{\dagger}$

\begin{tabular}{lccccc}
\hline Category & Conjoint dose & Hiroshima & Maleness & Years since birth & Intercept $^{\mathrm{a}}$ \\
\hline All cancers & -0.000081 & -0.000247 & $0.000602^{*}$ & 0.000004 & 0.001134 \\
$\quad(92$ cases $)$ & $(0.000252)$ & $(0.000275)$ & $(0.000266)$ & $(0.000017)$ & $(0.000260)$ \\
Leukemia & 0.0000003 & 0.000075 & 0.000281 & -0.000007 & 0.000266 \\
$\quad(33$ cases $)$ & $(0.000151)$ & $(0.000165)$ & $(0.000159)$ & $(0.000010)$ & $(0.000156)$ \\
"Heritable" & -0.000073 & -0.000156 & 0.000040 & 0.000007 & 0.000395 \\
$\quad(19$ cases) & $(0.000114)$ & $(0.000125)$ & $(0.000121)$ & $(0.000008)$ & $(0.000118)$ \\
Other & -0.000009 & -0.000165 & $0.000361^{*}$ & 0.000004 & 0.000473 \\
(40 cases) & $(0.000166)$ & $(0.000181)$ & $(0.000175)$ & $(0.000011)$ & $(0.000171)$ \\
\hline
\end{tabular}

${ }^{\dagger} n=72,216$ subjects.

${ }^{\text {a }}$ Adjusted for average number of years between bombings and births.

$* 0.01<P<0.05$. 
Little [1990] examined effects of parental exposures separately, finding no hint of a difference.

c. Because of the possibility that during the difficult, immediate post-war period in Japan, childhood leukemia was underdiagnosed, and so an "early" increase in the frequency of this disease in the children of the exposed was missed, Little [1992] reanalyzed our data for a time trend. None was observed; the constancy of diagnoses (especially in the children of the unexposed) suggests that underdiagnosis in the early years of the study did not significantly influence the study. Furthermore, had there been an excess of childhood leukemia in the children of the exposed, on the scale suggested by the Gardner study (see below) and had the diagnoses been missed, their deaths would have inflated some one or more of the 10 disease categories under which deaths were analyzed. There is no evidence for such an inflation of mortality in a particular disease category, neither in our analysis [Yoshimoto et al., 1991] nor in the reanalysis of Little [1991a, 1992].

The treatment of this latter point by the plaintiffs provides an example of the obfuscation to which I referred earlier. This consisted especially in raising doubts about the validity of the study, doubts whose quantitative implications had not been thought through. The barristers for the plaintiffs, noting the approximately 7 -fold greater sensitivity of mature and maturing sperm to the genetic effects of ionizing radiation [Russell, 1963], and noting that those fathers of the leukemic children who worked in Sellafield would be subjecting maturing sperm to radiation, strongly urged that the "Sellafield effect" especially reflected the radiation of mature sperm, and that the corresponding effect in Japan would result in a high frequency of leukemia in the children conceived just after the bombings and born during 1946, a frequency missed in our study because of poor diagnostic standards during the early years of our study. Aside from the conflict with the actual data, mentioned above, this suggestion requires an outlandish radiosensitivity of maturing and mature sperm. Since, as mentioned earlier, the "exposed" fathers in the study cohort had been employed at Sellafield for 6-13 years, only a fraction of the (maximum) dose of $200 \mathrm{mSv}-$ certainly less than 5\%-would have reached maturing and mature sperm. In the Japanese study, during May to November of 1946 (when all the children resulting from zygotes fertilized by sperm which were mature and maturing at the time of the bombing would have been born), 263 children were born to parents whose combined exposures were $\geq 0.01 \mathrm{~Sv}$ equivalent and 1,189 to parents receiving $<0.01 \mathrm{~Sv}$ equivalent. In the former group, the mean paternal gonad dose was $0.26 \mathrm{~Sv}$ equivalent and the mean maternal dose was $0.12 \mathrm{~Sv}$ equivalent. No cases of leukemia were detected in this group, but one case is on record among the children whose parent received $<0.01 \mathrm{~Sv}$ equivalent. If the (very approximately) $10 \mathrm{mSv}$ of radiation to mature and maturing sperm received by the Sellafield workers (a maximal dose estimate) was primarily responsible for the 6.4-fold increase in the frequency of childhood leukemia in Seascale, then the expectation in Japan would be (again, very approximately) for $260 / 10 \times 6.4 \times 263 \times 0.05 \%$, or 21.9 children with the disease on the basis of paternal radiation alone. (This calculation assumes childhood leukemia is due to a single dominant, completely penetrant gene and ignores a dose rate effect (see below), the assumptions most favorable to the plaintiffs' case.) While I attach little confidence to these precise numbers, it is clear the extrapolation of the Seascale findings to the 
Japanese situation requires a frequency of childhood leukemia in that early period which would not have gone undetected! Furthermore, the greater sensitivity of mature and maturing sperm (compared with spermatogonia) implied in their argument exceeds the Russell factor of 7 by a factor of at least 300 (although again a precise calculation is difficult).

The data on the genetic effects of the atomic bombs accumulated over the past 45 years in Japan of course extend far beyond the matter of childhood malignancies. The epidemiologic approach employed in Hiroshima and Nagasaki has been a cohort study, based on all the children born in these two cities between 1946 and 1985 to survivors who received significant amounts of radiation. The cohort consists of 31,150 children; there is a somewhat larger, age- and sex-matched cohort of children born in these two cities to parents who did not receive increased radiation from the bombings. Over the years, in a major collaborative effort between Japanese and American investigators, under the auspices of the Atomic Bomb Casualty Commission and its successor agency, the Radiation Effects Research Foundation, a wide variety of studies have been performed on these cohorts, or suitable subsets thereof. These studies include the following: frequency of stillbirth, frequency of congenital malformation, sex ratio, death among liveborn children up to an average age expectancy of 26 years, physical development at various ages, presence of selected chromosomal abnormalities (sex-chromosome aneuploidy, reciprocal translocations), occurrence of mutations affecting the electrophoretic mobility or physiological activity of a series of 30 polypeptides, and, of course, the cancer studies.

In recent years, these analyses have been presented on a variety of occasions, and I feel I can be quite brief in summarizing the findings [cf. Neel and Schull, 1991]. The basic analysis of these data employed, where feasible, a linear multiple regression model of occurrence of indicator on conjoint parental gonadal radiation dose, using the revised dose schedule which became available in 1986 (DS86). In no case was a regression statistically significant. Because the observations were all on the same cohorts, we felt it appropriate to combine these regressions, to obtain a single summary figure for the effect of the exposures. (For technical reasons, the regressions for sex-ratio, reciprocal translocations, and physical development were not incorporated into this summary analysis.) We also estimated the contribution, each generation, of parental mutation to the various indicators, and summed these contributions. The mutational doubling dose is defined as the amount of ionizing radiation that will produce, with reference to the indicators under study, the same frequency of mutations as would occur spontaneously each generation. In these data the estimated total contribution from spontaneous mutation in the preceding generation to the sum of the endpoints pursued is between 0.0063 and 0.0084 . The combined regression term is $+0.00375 / \mathrm{Sv}$ equivalent. The doubling dose is derived by dividing the latter into the former, and is estimated at between 1.7 and $2.2 \mathrm{~Sv}$ equivalents. The range indicates uncertainty about the exact mutational contribution to some of the indicators and does not include a statistical error of estimation [for a discussion of the problem of assigning an error term, see Neel and Schull, 1991]. I note that ordinarily one does not manipulate non-significant findings in this fashion, but remind you that we accept that the radiation exposure did result in some mutations in Hiroshima and Nagasaki. We are not testing the hypothesis of radiation-induced mutations in this study but rather accepting the data at face value in order to derive an 
estimate. I should further emphasize that this estimate is an average for the sexes; in the absence of any statistically significant findings for the sexes combined it has not seemed meaningful to subdivide the data further and analyze for the effects of maternal and paternal exposure separately.

Most human exposures to ionizing radiation will be relatively low level, chronic, or intermittent, rather than the relatively high-level exposures sustained by a sizable fraction of atomic bomb survivors. This was certainly the case at Sellafield. One of the most significant findings to emerge from the extensive studies of mouse radiation genetics, to be discussed shortly, was that the genetic yield of a given amount of ionizing radiation is higher if the radiation is delivered acutely rather than chronically. The exact differential depended on the endpoint under study, but for "point mutations," as studied in the male-based, 7-specific-locus test of Russell [1951], the conversion factor was about 3 at the gonadal doses of 3 and $6 \mathrm{~Gy}$ employed in the mouse experiments [Russell et al., 1958]. Accepting the parameters developed by Abrahamson and Wolff [1976] for the linear and quadratic components of the radiation effect for the Russell system, and considering the distribution of the estimated parental gonad exposures in the study in Japan, we have elected to employ a lower dose rate factor, of 2 , for the human material. The doubling dose for chronic ionizing radiation in humans is therefore estimated at between 3.4 and $4.5 \mathrm{~Sv}$ equivalents.

2. A comparison with the murine data. During and following World War II, a very major program in the radiation genetics of mice came into being, with the thought that the domestic mouse was the best human surrogate available in genetic risk setting. On the basis of segments of those data, but especially the results of the Russell 7-locus test system, the genetic doubling dose of acute radiation for mice has been set at about 0.4 Gy [Lüning and Searle, 1971] and this estimate was often extrapolated to humans [United Nations, 1977, 1982, 1986, 1988]. Given the dose rate factor for mice mentioned earlier, this translated to a doubling dose for chronic ionizing radiation of about $1.2 \mathrm{~Gy}$. (Under these circumstances, the genetic effectiveness of $1.0 \mathrm{~Gy}$ should be the same as $1.0 \mathrm{~Sv}$ equivalent.) The discrepancy between this estimate and that which we were developing for humans was somewhat disturbing, to the extent that in 1989 I asked Dr. Susan Lewis to join me in a reanalysis of the murine data [Neel and Lewis, 1990]. As we got into our subject, we became aware of many reasons to be cautious in a direct comparison of the two species with respect to such endpoints as congenital malformations, stillbirths, or survival of liveborn offspring. The most appropriate comparison with the human estimate seemed to be that derived from all the different specific locus or phenotype test systems developed for the mouse, including some whose results had received relatively little attention because the smallness of the radiation effect seems to have raised questions concerning the reliability of the system. Table III summarizes the results obtained with acute ionizing radiation for all 8 of these systems. The simple unweighted average of these various estimates of a doubling dose is $1.35 \mathrm{~Gy}$. The implication is that the genetic loci incorporated into the Russell 7-locus test are more mutable than the loci which are the basis for the other test systems; elsewhere we have presented reasons why this might be the case [Neel and Lewis, 1990]. Employing a dose rate factor of 3 for the extrapolation from acute to chronic radiation under these circumstances, we obtained an estimate of the doubling dose of chronic radiation of $4.05 \mathrm{~Gy}$, in surprising 
TABLE III. Summary of the Estimated Gametic Doubling Doses for the Acute, "High-Dose" Radiation of Spermatogonia Yielded by the Various Specific-Locus/Specific-Phenotype Systems Developed in the Laboratory Mouse*

\begin{tabular}{|c|c|c|}
\hline System & Doubling dose (Gy) & Strain of origin of treated males \\
\hline Russel 7-locus & 0.44 & $101 \times \mathrm{C} 3 \mathrm{H}$ \\
\hline Dominant visibles & 0.16 & Various \\
\hline Dominant cataract & 1.157 & 101/E1 $\times \mathrm{C} 3 \mathrm{H} / \mathrm{E} 1$ \\
\hline Skeletal malformations & 0.26 & 101 \\
\hline Histocompatibility loci & $>2.60$ & C57B $1 / 6 \mathrm{JN}$ \\
\hline \multirow{3}{*}{ Recessive lethals } & 0.51 & DBA \\
\hline & $0.80\} 1.77$ & $\mathrm{C} 3 \mathrm{H} / \mathrm{HeH} \times 101 / \mathrm{H}$ \\
\hline & $4.00)$ & $\mathrm{CBA}, \mathrm{C} 3 \mathrm{H}$ \\
\hline Loci encoding for proteins & 0.11 & Various \\
\hline Recessive visibles & 3.89 & $\mathrm{C} 3 \mathrm{H} / \mathrm{HeH} \times 101 / \mathrm{H}$ \\
\hline Average & 1.35 & \\
\hline
\end{tabular}

*Details concerning the source of the data and the calculations can be found in Neel and Lewis [1990].

agreement with the estimate based on the studies in Japan. I hasten to add that there is no theoretical reason to expect such agreement, but it is somehow reassuring.

One set of murine data deserves special mention in the context of the Gardner study, namely, Nomura's data on cancer, including leukemia, in the offspring (followed up to 8 months) of male mice receiving rather large doses (up to $5.04 \mathrm{~Gy}$ ) of acute ionizing radiation [Nomura, 1982, 1990, 1991]. The plaintiffs placed great reliance on these data. In considering their relevance, it must be recalled that in the early days of mouse genetics, many strains were specifically selected for high cancer frequencies, and it is often difficult to ensure that modern strains do not incorporate some of this ancestry. The spectrum of spontaneous malignancies in the mice employed by Nomura differed markedly from the human spectrum. For instance, in the two strains employed the frequencies of leukemia were $1.0 \%$ and $0.4 \%$, respectively, contrasted with the worldwide frequency of childhood leukemia in humans (including our own study) of about $0.05 \%$. Furthermore, the childhood tumors with the strongest genetic component in humans, retinoblastoma, Wilms' tumor, and, possibly, neuroblastoma, which would be landmark tumors in any study of the genetic effects of radiation on humans, were not recognized in the mouse. Be this as it may, following the exposure of male mice to an acute radiation dose of $5.04 \mathrm{~Gy}$, the frequency of leukemia in the offspring increased to $4.75 \%$ and $3.91 \%$, respectively, in the strains employed by Nomura. Thus, in the Nomura system, a dose of $0.2 \mathrm{~Gy}$ (which is a maximum estimate of the average amount of badge dose radiation received by the Sellafield fathers) should increase the leukemia frequency by only $15-35 \%$, whereas in the work of Gardner and associates, this same dose to fathers resident in Seascale is reported to result in a $640 \%$ increase in leukemia and lymphoma. I make the Sellafield findings to indicate an 18- to 43-fold greater sensitivity of this endpoint than Nomura's findings. Furthermore, a dose rate factor of 3 must be invoked to adjust for the chronic nature of the radiation experienced by Sellafield workers, and a further factor of approximately 2 must be invoked to adjust for the fact that the Sellafield exposures were measured at the surface of the trunk rather than calculated for the gonad. These two adjustments require a factor of 6 , and the Gardner findings now 
acquire a sensitivity 108-258 times greater than those of Nomura, if you accept the appropriateness of the comparison, which I do not. (This calculation of necessity neglects the possible role of internal emitters of ionizing radiation in the Sellafield data, but from the information available it seems very unlikely to add more than $20 \%$ to the collective equivalent dose to the testes associated with the Seascale births [Wakeford et al., 1994].

3. Further on why the association reported by Gardner and associates cannot represent cause and effect. We have just seen that at the phenomenological level, neither the data from Japan nor from mice support a genetic explanation of the association reported by Gardner and colleagues. Two additional arguments cast further doubt on a genetic explanation for the observed association.

a. The genetics of human leukemia. Unlike such malignancies of childhood as retinoblastoma and Wilms' tumor, for which there is clear evidence that an abnormal allele transmitted from a parent can play a major role in the causation of the tumor, such evidence has not been forthcoming for the childhood leukemias. These leukemias, collectively, are some 10 times more common than retinoblastoma, yet there have been reported only a relatively small number on non-syndromic family clusters [Blattner et al., 1976; Draper et al., 1977; Felix et al., 1992; Fraumeni et al., 1969; Gunz et al., 1978; Miller, 1971; Pendergrass et al., 1975; Snyder et al., 1970; Steinberg, 1960; Zuelzer and Cox, 1969]. In the past, the fatal nature of childhood leukemia has not permitted an adequate test of a genetic hypothesis. Now, however, with the improved treatment of childhood leukemia characterizing the last 30 years, there are long-term survivors who, reaching adulthood, are reproducing. Draper [1989] in a review finds that of some 40 children born to such survivors, none has developed similar disease. Were 40 children born to survivors of retinoblastoma, the expectation (allowing for the fact that some retinoblastomas are due only to somatic mutations) would be that about 8 children would themselves develop retinoblastoma. Recently, Felix et al. [1992] have reported what is apparently the first example of parent-offspring transmission of childhood leukemia. Also, of 118 children of men and women who had survived a closely related malignancy, namely, early-onset nonHodgkin's lymphoma, none has developed leukemia nor non-Hodgkin's lymphoma [Draper, 1989].

On the basis of present evidence, not more that $5 \%$ of childhood leukemia can be attributed to a genetic basis such as accounts for familial retinoblastoma. This is the fraction which should be responsive to a radiation-induced mutation in the appropriate gene in a parent. I remind you that the Sellafield exposures were chronic, which by comparison with the Japanese experience should reduce any genetic yield by $1 / 2$, and the fact that badge, not gonad, doses were employed should introduce another factor of $\sim 1 / 2$. Earlier, I quoted Little's estimate of a 50- to 80 -fold discrepancy between the Gardner results and the Hiroshima-Nagasaki findings. That was at the phenomenological level. Now we can add genetic considerations to the comparison, and incorporate into the calculation the three corrections just mentioned; the discrepancy is between $50 \times 20 \times 2 \times 2=4,000$-fold, and $80 \times 20 \times 2 \times 2=$ 6,400 -fold.

There is another approach to quantifying the discrepancy, based on the a-bombbased estimate of the doubling dose, of $\sim 4 \mathrm{~Sv}$ equivalents of chronic ionizing radi- 
ation. Assuming this estimate applies to the gene or genes responsible for childhood leukemia, the Gardner data indicated a 6.4-fold increase in leukemia following an average paternal dose of chronic ionizing radiation of about $0.2 \mathrm{~Sv}$ equivalent. Again assuming that the genetic component in childhood leukemia (i.e., the component that would respond to radiation) is approximately $5 \%$, then in the Gardner data, the doubling dose for "genetic"childhood leukemia is $0.2 \mathrm{~Sv}$ equivalent $/(6.4 \times 20 \times 2)=$ $0.0008 \mathrm{~Sv}$ equivalent, a 5,000-fold discrepancy with the multifaceted estimate of the doubling dose derived from the a-bomb data.

The barristers for the plaintiffs sought to explain this discrepancy with the possibility that there were multiple genes in any one of which a mutation in a parent could be associated with leukemia in a child, plus the possibility that these genes were unusually sensitive to the genetic effects of radiation. It is true that in the Russell 7-locus test, there is an approximately 18 -fold difference between the most- and the least-radiation sensitive genes [Searle, 1974]. Let us assume that mutation at any one of five different genetic loci can result in childhood leukemia, and the loci involved are 10 times more sensitive to the mutagenic effects of ionizing radiation than the average. Even if both these factors are applied to the Japanese data--an extraordinary concession-there would still be a 100 -fold discrepancy between the results of the two studies.

b. The non-specificity of the genetic affects of ionizing radiation. Finally, I note that the damage of ionizing radiation to DNA is generalized, "shotgun" in nature. As noted, the findings of the Gardner studies imply genetic sensitivities some 4,0006,000 times greater than have been obtained in other studies on the genetic effects of radiation. There thus should have been a spectacular increase in the frequency of other genetic disease resulting from newly arisen mutations in the area covered by the Gardner studies. Although this expectation does not as yet appear to have been vigorously pursued, Jones and Wheater [1989] reported no increase in abnormal obstetrical outcomes in West Cumberland Hospital, which services the area covered by the Gardner studies.

4. The results of other comparable epidemiological studies. Thus far the results of three attempts to duplicate the findings of the Gardner study have been published. The first of these attempts involved a case-control study of leukemia and non-Hodgkin's lymphoma in the district surrounding the Dounreay nuclear installation in Scotland, where an apparent excess incidence of these two diseases had previously been reported [Committee on the Medical Aspects of Radiation in the Environment, 1988; Wakeford and Wilkie, 1989]. The study revealed no excess risk in association with paternal employment at the Dounreay plant [Urquhart et al., 1991]. However, the study was of such low statistical power that the results were compatible with the results of either the a-bomb or the Gardner studies [Little, 1991b]. Subsequently, Kinlen et al. [1993a] conducted a study of leukemia and non-Hodgkin's lymphoma in persons under 25 in the whole of Scotland, their survey thus including the area studied by Urquhart et al. [1991]. Again, no association with paternal employment at a nuclear installation was observed, but now it was felt that the results were statistically inconsistent with the findings of Gardner et al. [1990a,b], [Kinlen, 1993].

The second effort at confirmation of the Sellafield association was based on a case-control study of leukemia in children under the age of 15 living in the vicinity 
of various nuclear facilities in the Province of Ontario, Canada [McLaughlin et al., 1992]. In this instance, no clusters of childhood leukemia had been established. This study found no association of childhood leukemia with fathers' employment at a nuclear installation; the power of the study was such that the authors conclude the results are not consistent with those of the Gardner group.

A third case-control study was conducted by Roman and associates [1993] on leukemia and non-Hodgkin's lymphoma among children aged 0-4 years living in the West Berkshire and North Hampshire health districts of England. This area contains two nuclear installations and in it an excess of childhood leukemia had previously been documented [Roman et al., 1987]. Five (9\%) of the 54 cases and $14(4 \%)$ of the 324 controls had fathers or mothers, or both, who had been employed by the nuclear industry (relative risk 2.2; CI 0.6-6.9). Where the workers had been badged, the cumulative doses were very small, on the order of background, the largest $5 \mathrm{mSv}$ equivalents. The investigators very prudently conclude that "if the association between paternal preconceptual exposure to radiation and childhood leukemia we found is not a chance finding, the effect is unlikely to be due to paternal exposure to the forms of external penetrating ionizing radiation measured by monitoring devices."

In England, there does not seem to be a general increase in cancer near nuclear installations, with the possible exception of leukemia in young people [Forman et al., 1987]. This fact, especially in light of the general failure to confirm the results of Gardner and associates, has prompted considerable interest in some non-radiogenic cause of leukemia clusters. For some years, Kinlen and associates [Kinlen, 1988; Kinlen et al., 1990; Kinlen and Hudson, 1991] have been exploring the hypothesis that leukemia clusters are associated with population mixing, i.e., with the coming together of individuals who have previously lived well apart from one another. It is suggested that these individuals introduce each other to formerly endemic viruses, and the resultant flurry of viral infections is followed by an excess of leukemia in children. Nuclear installations have usually been located in remote areas, so that the work force must be recruited from a wide area. Kinlen et al. [1993b] point out that the previously sparsely populated area in which the Dounreay nuclear installation is located is also an area of heavy population influx because of the in-migration of workers in the North Sea oil fields. In this connection, Kinlen [1993] also points out that the excess of leukemia in Seascale is not confined to children born there (the subjects of the Gardner study), but also occurs in children born elsewhere but who move to Seascale at a young age. The possibility that an unknown infectious agent might be implicated in the clusters of childhood leukemia in England and Scotland has been further advanced by the studies of Alexander and associates [Alexander, 1992; Alexander et al., 1990, 1992], who have observed that, in general, cases of leukemia live close to one another more often than controls and tend to be synchronous in time of onset.

At the same time that interest has been growing in the possibility of an infectious etiology as the basis for leukemia clusters, a number of investigators [Boaag and Newell, 1991; Cuzick and Edwards, 1990; Openshaw et al., 1988; Stone, 1988; Whittemore et al., 1987] have been vigorously exploring the proper statistical approach to the role of chance in creating disease clusters. Indeed, the subject of clustering of health events has created so much interest (and controversy) that the American Journal of Epidemiology in 1990 published a most useful special 
supplement reporting the results of a national conference sponsored by the Center for Disease Control [National Conference on Clustering of Health Events, 1990]. Even if a disease is distributed at random with respect to population density, by chance there may be clusters which taken out of the context of the totality of the area surveyed, may appear to be significant. The proper test for the significance of a cluster within a defined geographic area after the fact (i.e., after its preliminary identification) is not to contrast frequency of disease within the cluster area with random expectation, but the question of how to correct for the role of chance in producing apparent clusters when the distribution of disease cases through a large, presumably heterogeneous area is unknown is proving difficult. At the very least, some equivalent to the adjustment made when multiple tests of significance are performed, such as a Bonferroni-type adjustment, seems indicated.

5. A contrast of the findings in Seascale with those in surrounding communities. Even as the studies summarized in the preceding section were in progress, it was recognized that the Gardner studies had involved only a fraction of the total population of Sellafield plant employees living in the vicinity of the Sellafield installation, and investigators began to cast a wider epidemiological net throughout Cumbria. Parker et al. [1993] established that in all of the Cumbria district (within which Seascale is located) there were, in the period 1950-1989, 10,363 children born to fathers who were employed at Sellafield at or before the date of conception of the child. The estimated total collective paternal preconceptual dose for this entire group was 539 person Sv equivalents. Only $7 \%$ of this dose was associated with the fathers of children born in Seascale. There was no excess of leukemia in the remaining children. They conclude that their finding is "statistically incompatible with the proportion of risk that would have to be associated with Seascale births if these occupational radiation exposures were to be sufficient to explain the excess of childhood leukemia cases in Seascale." Stated otherwise, the alleged leukemogenic effect of paternal exposure to ionizing radiation at Sellafield appeared to be unique to the Seascale district.

Concurrently, Craft et al. [1993] analyzed the occurrence of cancer (including leukemia) in young people in the north of England by census wards for the period 1968-1985. This analysis identified several cancer "hot spots," including Seascale. One of these additional hot spots, for acute lymphoblastic leukemia, was the ward of Egremont North, some $7 \mathrm{~km}$ north of the Sellafield installation. There were four children in this cluster; none of the fathers of these children were exposed to ionizing radiation at Sellafield prior to the conception of the children (even though employment at Sellafield was common among the inhabitants of North Egremont) (Wakeford, personal communication).

As the various inconsistencies in their case discussed in these last two sections began to become apparent, counsel for the plaintiffs began to refer to a factor $\mathrm{X}$ at work in Seascale, which factor was not present elsewhere and somehow potentiated the expression of the leukemogenic mutations postulated to have resulted from the paternal exposures at Sellafield. Unfortunately for their case, this postulate still requires an induced mutation rate in response to these workplace exposures which is completely at odds with both the murine data and the Japanese experience. Equally unfortunate for their thesis are the clusters of leukemia in the vicinity of nuclear plants where there is no excess of paternal exposures in the nuclear workplace. 
On October 8, 1993, after some 4 months of deliberation, the Hon. Mr. Justice French submitted a closely reasoned verdict which found for the defendant so convincingly that it is unlikely there will be an appeal. I quote briefly from his verdict:

"In the result, the mechanisms proposed by the plaintiffs to account for the astonishingly larger mutation rate which the Gardner hypothesis requires, over and above any human experience or murine experiment, remain, I consider, in the present state of scientific knowledge, speculative.... The explanation based on a supra multiplicative effect between two factors (PPI ${ }^{1}$ and a "Seascale" factor in the form, e.g., of a virus or chemical) seems to me to be speculative also. Further, it poses two major problems. First, as I have said, it presupposes the high mutation rate which it sets out to explain; otherwise there would be nothing for the "Seascale factor" to synergize with. Secondly, it does not explain how the excess of leukemias can occur, e.g., in Egremont North involving children of fathers with no or, at most, trivial PPI. If some factors neither or none of which is PPI can cause leukemias in Egremont North, why is PPI necessary to explain the Seascale leukemias? Why should the Egremont North factors not have operated by themselves in Seascale with PPI, albeit present among Seascale fathers, present as an irrelevance?... In my judgment, however, on the evidence before me the scales tilt decisively in favour of the defendants and the plaintiffs, therefore, have failed to satisfy me on the balance of probabilities that PPI was a material contributory cause of the Seascale excess or, it must follow, of (a) the leukemia of Dorothy Reay or (b) the $\mathrm{NHL}^{2}$ of Vivien Hope." [pp 73-74].

\section{WHAT CAN BE DONE TO MINIMIZE FALSE POSITIVE OUTCOMES IN GENETIC EPIDEMIOLOGY}

I have probably given you much more detail concerning this fascinating imbroglio than any of you were hankering after this afternoon, but felt it important to get a full account of the matter into the genetic literature. While dilemmas such as this are what the judiciary is trained to meet, I suggest conventions can be devised which should lessen the possibility of such expensive and time-consuming extravaganzas in the future. Inasmuch as the continuing occurrence of highly visible false positive results will not contribute to the image of genetic epidemiology, it behooves us to take this matter seriously.

In a sense, we find ourselves in the position of general epidemiologists in the 1950 s and 1960s, when the case-control approach to a variety of epidemiological studies began to be extensively employed. Unusual and non-reproducible findings became sufficiently prevalent that a group of investigators organized a Symposium on the Case-Control Method, held in Bermuda in April of 1978, the very useful proceedings of which were subsequently published [Ibrahim, 1978]. Now, 15 years later, many of the issues discussed at that Conference are still with us. I need hardly

\footnotetext{
${ }^{1} \mathrm{PPI}=$ paternal preconception irradiation.

${ }^{2} \mathrm{NHL}=$ non-Hodgkin's lymphoma.
} 
to remind you of the recent confusion concerning the linkage relationships of possible major genes associated with schizophrenia and the affective disorders. Furthermore, our sister field of teratogenesis is confronted with many of the same problems as those of genetic epidemiology [cf. Brent and Beckman, 1990], and there is reason to make common cause.

Guided by that Conference, plus the sometimes conflicting results of recent applications of genetic epidemiology, and especially the study I have reviewed in such detail, I am moved at this time to make four suggestions. The first two, unfortunately, if implemented are expensive, but in the end, to the extent that they reduce public and scientific confusion, and render multiple repeat studies unnecessary, are probably cost effective.

The first suggestion is to pursue prospective-cohort studies wherever possible, studies in which the hypothesis or hypotheses to be tested are clearly defined. This is not the place for a detailed discussion of the relative merits of the case-control and prospective-cohort approaches. The latter generally permits a cleaner research design, but it must be admitted that there will be many situations where a clear statement of hypothesis is impossible, and one must engage in the fishing expedition to which the case-control study lends itself. Furthermore, funding agencies and those who fund them - and even investigators - cannot always summon the patience which a prospective study requires.

The second positive suggestion is that whenever possible, epidemiological studies designed to clarify a troublesome issue need to be pursued in duplicate, simultaneously. Any finding not replicated in parallel studies is suspect. Such a tacit policy will require a degree of communication between investigators and a viewpoint on the part of funding agencies that do not exist at present. All over the world, most of the funding for large-scale epidemiological studies is now federal. Many applications for study support will be stimulated by a government Request for Proposal, emanating, in the United States, e.g., from one of our National Institutes. Such requests could be committed to the support of at least two proposals, so planned that their results would be immediately and directly comparable. Some funding sources are already moving in this direction; it is an interesting question as to how directive these sources should become to ensure cross-comparability between the studies they fund. Conversely, perhaps a Society such as ours can serve as an incubator for major studies planned from the beginning in duplicate on two independent and even cross-national populations.

There will be situations where completely independent duplicate studies are impractical. My own experience leads me to think of the complex follow-up studies on the delayed effects of the atomic bombs. Even here, the need for independent appraisals of the data set can be met. First, the research design must be scrutinized at the outset by a broad spectrum of research interests, in an effort to avoid the kinds of oversights that so often surface in retrospect. Second, the data, when available, can be made accessible to qualified, independent investigators, providing, of course, that the primary investigator has first access.

The third suggestion is really only an affirmation of two established epidemiological principles. One is that because of the ever-present problem of establishing suitable controls, one attempts to establish a dose-rate effect within the "exposed" category. This implies that regression-type analyses (rather than $2 \times 2$ contrasts) be 
employed whenever possible. The other is that conclusion regarding causality should be reinforced, where appropriate, by controlled studies involving an animal model.

It seems certain that future epidemiological studies with a strong genetic component can only become more complex. Our ability to adjust to this growing complexity will be a test of the maturity and sophistication of genetic epidemiology. My fourth and final suggestion is that we all develop a very healthy skepticism toward even our own results, especially if the "result" is in obvious conflict with the results of previous studies. With reference to the study which provided the text for this presentation, I would suggest there were already in the genetic literature at the time of the publication of the Gardner study so many indications that the results constituted an extreme outlier, that much greater caution in their interpretation was called for than was exercised. Perhaps, in this connection, the future programs of this Society can provide an arena in which this skepticism can be practiced. It would be especially helpful if this exercise were prepublication, while manuscripts and conclusions are still in the formative stages.

In closing, I thank you for the privilege of serving as your president these past 2 years. Some of you will recall the banner I unfurled at our first meeting: "Beyond the Human Genome Project: Genetic Epidemiology." If we as a Society respond to this trend wisely, I would expect that within the next few years we should become a lively crossroads for much of the upcoming activity in genetic epidemiology.

\section{ACKNOWLEDGMENTS}

The author's involvement in the studies of the genetic effects of the atomic bombs has been funded by the U.S. Department of Energy and its predecessor organizations.

\section{REFERENCES}

Abrahamson S, Wolff S (1976): Reanalysis of radiation-induced specific locus mutations in the mouse. Nature 264:715-719.

Alexander FE (1992): Space-time clustering of childhood acute lymphoblastic leukaemia: Indirect evidence for a transmissible agent. Br J Cancer 65:589-592.

Alexander FE, McKinney PA, Moncrieff KC, Cartwright RA (1990): Community lifestyle characteristics and risk of acute lymphoblastic leukaemia in children. Lancet 336:1461-1465.

Alexander FE, McKinney PA, Moncrieff KC, Cartwright RA (1992): Residential proximity of children with leukaemia and non-Hodgkin's lymphoma in three areas of Northern England. Br J Cancer 65:583-588.

Black D (1984): “Investigation of the Possible Increased Incidence of Cancer in West Cumbria." London: Her Majesty's Stationery Office.

Blattner W, Strober W, Muchmore A, Blaese R, Broder S (1976): Familial chronic lymphocytic leukemia: Immunologic and cellular characterization. Ann Intern Med 84:554-557.

Boaag J, Newell J (1991): The detection of clusters in rare diseases. J R Stat Soc A154:143-155.

Brent RL, Beckman DA (1990): Environmental teratogenesis. Bull NY Acad Med 66:123-163.

Committee on the Medical Aspects of Radiation in the Environment (1988): "Second Report: Investigation of the Possible Increased Incidence of Leukaemia in Young People Near the Dounreay Nuclear Establishment, Caithness, Scotland." London: Her Majesty's Stationery Office.

Craft AW, Parker L, Openshaw S, Charlton M, Newell J, Birch J, Blair V (1993): Cancer in young people in the north of England, 1968-1985: Analysis by census wards. J Epidemiol Community Health 47:109-115. 
Cuzick J, Edwards R (1990): Spatial clustering for inhomogeneous populations. J R Stat Soc B 53:73-104. Draper GJ (1989): General overview of studies of multigeneration carcinogenesis in man, particularly in relation to exposure to chemicals. In Napalkov NP, Rice GM, Tomatis L, Yamasaki H (eds): "Perinatal and Multigeneration Carcinogenesis." Lyon: International Agency for Research on Cancer, pp 275288.

Draper GJ, Heaf MM, Kinnier Wilson LM (1977): Occurrence of childhood cancers among sibs and estimation of familial risks. J Med Genet 14:81-90.

Draper GJ, Stiller CA, Cartwright RA, Craft AW, Vincent TJ (1993): Cancer in Cumbria and in the vicinity of the Sellafield nuclear installation, 1963-1990. Br Med J 306:89-94.

Felix CA, D’Amico D, Mitsudomi T, Nau MM, Li FP, Fraumeni FJ, Cole DE, McCalla J, Reaman GH, Whang-Peng J, Knutsen T, Minna JD, Poplack DG (1992): Absence of hereditary p53 mutations in 10 familial leukemia pedigrees. J Clin Invest 90:653-658.

Forman D, Cook-Mozaffari P, Darby S, Davey G, Stratton I, Doll R, Pike M (1987): Cancer near nuclear installations. Nature 329:449-505.

Fraumeni JF, Vogel CL, DeVita VT (1969): Familial chronic lymphocytic leukemia. Ann Intern Med 71:279-284.

Gardner MJ, Hall AJ, Downes S, Terrell JD (1987a): Follow-up study of children born elsewhere but attending schools in Seascale, West Cumbria (schools cohort). Br Med J 295:819-822.

Gardner MJ, Hall AJ, Downes S, Terrell JD (1987b): Follow-up study of children born to mothers resident in Seascale, West Cumbria (birth cohort). Br Med J 295:822-827.

Gardner MJ, Snee MP, Hall AJ, Powell CA, Downes S, Terrell JD (1990a): Results of case-control study of leukaemia and lymphoma among young people near Sellafield nuclear plant in West Cumbria. Br Med J 300:423-429.

Gardner MJ, Hall AJ, Snee MP, Downes S, Powell CA, Terrell JD (1990b): Methods and basic data of case-control study of leukaemia and lymphoma among young people near Sellafield nuclear plant in West Cumbria. Br Med J 300:429-434.

Gunz FW, Gunz JP, Vincent PC, Bergin M, Johnson FL, Bashir H, Kirk RL (1978): Thirteen cases of leukemia in a family. J Natl Cancer Inst 60:1243-1250.

Ibrahim MA (1978): The case-control study: Consensus and controversy. J Chronic Dis 32:1-144.

Jones KP, Wheater AW (1989): Obstetric outcomes in West Cumberland Hospital: Is there a risk from Sellafield? I R Soc Med 82:524-527.

Kinlen L (1988): Evidence for an infective cause of childhood leukaemia: Comparison of a Scottish new town with nuclear reprocessing sites in Britain. Lancet 2:1323-1327.

Kinlen LJ (1993): Can paternal preconceptual radiation account for the increase of leukaemia and nonHodgkin's lymphoma in Seascale? Br Med J 306:1718-1721.

Kinlen LJ, Hudson C (1991): Childhood leukaemia and poliomyelitis in relation to military encampments in England and Wales in the period of national military service, 1950-63. Br Med J 303:1357-1362.

Kinlen LJ, Clarke K, Hudson C (1990): Evidence from population mixing in British new towns 1946-85 of an infective basis for childhood leukaemia. Lancet 336:577-582.

Kinlen LJ, Clarke K, Balkwill A (1993a): Paternal preconceptional radiation exposure in the nuclear industry and leukaemia and non-Hodgkin's lymphoma in young people in Scotland. Br Med J 306:1153-1158.

Kinlen LJ, O’Brien F, Clarke K, Balkwill A, Matthews F (1993b): Rural population mixing and childhood leukaemia: Effects of the North Sea oil industry in Scotland, including the area near Dounreay nuclear site. Br Med J 306:743-748.

Little MP (1990): A comparison between the risks of childhood leukaemia from parental exposure to radiation in the Sellafield workforce and those displayed among the Japanese bomb survivors. $J$ Radiol Prot 10:185-198.

Little MP (1991a): A comparison of the apparent risks of childhood leukaemia from parental exposure to radiation in the six months prior to conception in the Sellafield workforce and the Japanese bomb survivors. J Radiol Prot 11:77-90.

Little MP (199lb): A comparison of the risks of childhood leukaemia from parental preconception exposure to radiation in the Sellafield and Dounreay workforces and the Japanese bomb survivors. J Radiol Prot 11:231-240.

Little MP (1992): The risks of leukaemia and non-cancer mortality in the offspring of the Japanese bomb survivors and a comparison of leukaemia risks with those in the offspring of the Sellafield workforce. J Radiol Prot 12:203-218. 
Little MP (1993): A comparison of the risks of leukaemia in the offspring of the Japanese bomb survivors and those of the Sellafield workforce with those in the offspring of the Ontario and Scottish workforces. J Radiol Prot 13:161-175.

Lüning KG, Searle AG (1971): Estimates of the genetic risks from ionizing radiation. Mutat Res 12:291304.

McKinney PA, Alexander FE, Cartwright RA, Parker L (1991): Parental occupations of children with leukaemia in West Cumbria, North Humberside, and Gateshead. Br Med J 302:681-687.

McLaughlin JR, Anderson TW, Clarke EA, King W (1992): “Occupational Exposure of Fathers to Ionizing Radiation and the Risk of Leukaemia in Offspring - A Case-Control Study." Ottawa: Atomic Energy Control Board, pp ix, 46, and 4 appendices.

Miller RW (1971): Deaths from childhood leukemia and solid tumors among twins and other sibs in the United States, 1960-1967. J Natl Cancer Inst 46:203-209.

National Conference on Clustering of Health Events (1990): Clustering of health events. Am J Epidemiol 132:S1-202.

Neel JV, Lewis SE (1990): The comparative radiation genetics of humans and mice. Annu Rev Genet 24:327-362.

Neel JV, Schull WJ (1991): "The Children of Atomic Bomb Survivors: A Genetic Study:" Washington, DC: National Academy Press, pp vi, 518.

Nomura $\mathrm{T}$ (1982): Parental exposure to X-rays and chemicals induces heritable tumours and anomalies in mice. Nature 296:575-577.

Nomura T (1990): Of mice and men? Nature 345:671.

Nomura T (1991): Parental exposure to radiation and offspring cancer in mice. Reanalysis and new evidence. J Radiat Res (Suppl 2): 64-72.

Openshaw S, Craft AW, Charlton M, Birch JM (1988): Investigation of leukemia clusters by use of a geographical analysis machine. Lancet 1:272-273.

Parker L, Craft AW, Smith J, Dickinson H, Wakeford R, Binks K, McElvenny D, Scott L, Slovak A (1993): Geographical distribution of preconceptual radiation doses to fathers employed at the Sellafield nuclear installation, West Cumbria. Br Med J 307:966-971.

Pendergrass TW, Stoller RG, Mann DL, Halterman RH, Fraumeni JF (1975): Acute myelocytic leukaemia and leukaemia-associated antigens in sisters. Lancet 2:429-431.

Priest GL (1990): The new legal structure of risk control. Daedalus 119:207-227.

Roman E, Beral V, Carpenter L, Watson A, Barton C, Ryder H, Aston DL (1987): Childhood leukaemia in the West Berkshire and Basingstoke and North Hampshire District Health Authorities in relation to nuclear establishments in the vicinity. Br Med J 294:597-602.

Roman E, Watson A, Beral V, Buckle S, Bull D, Baker K, Ryder H, Barton C (1993): Case-control study of leukaemia and non-Hodgkin's lymphoma among children aged 0-4 years living in West Berkshire and North Hampshire health districts. Br Med J 306:615-621.

Russell WL (1951): X-ray induced mutations in mice. Cold Spring Harbor Symp Quant Biol 16:327-336.

Russell WL (1963): The effect of radiation dose rate and fractionation on mutation in mice. In Sobels F (ed): "Repair From Genetic Radiation." Oxford: Pergamon Press, pp 205-217, 231-235.

Russell WL, Russell LB, Kelly EM (1958): Radiation dose rate and mutation frequency. Science 128:15461550.

Searle AG (1974): Mutation induction in mice. In Lett JT, Adler HI, Zelle M (eds): "Advances in Radiation Biology." New York: Academic Press, Vol 4, pp 131-207.

Snyder AL, Li FP, Henderson ES, Todaro GJ (1970): Possible inherited leukaemogenic factors in familial acute myelogenous leukaemia. Cancer 13:586-589.

Steinberg A (1960): The genetics of acute leukemia in children. Cancer 13:985-999.

Stone RA (1988): Investigations of excess environmental risks around putative sources: Statistical problems and a proposed test. Stat Med 7:649-660.

United Nations (1977): "Sources and Effects of Ionizing Radiation." United Nations Sales Publication E.77.IX.1, United National Scientific Committee on the Effects of Atomic Radiation, 1977 Report to the General Assembly, With Annexes. New York: United Nations.

United Nations (1982): "Ionizing Radiation: Sources and Biological Effects." United Nations Sales Publication E.82.IX.8, United Nations Scientific Committee on the Effects of Atomic Radiation, 1982 Report to the General Assembly, With Annexes. New York: United Nations. 
United Nations (1986): "Genetic and Somatic Effects of Ionizing Radiation." United Nations Sales Publication E.86.IX.9, United Nations Scientific Committee on the Effects of Atomic Radiation, 1986 Report to the General Assembly, With Annexes. New York: United Nations.

United Nations (1988): "Sources, Effects and Risks of Ionizing Radiation." United Nations Sales Publication E.88.IX.1, United Nations Scientific Committee on the Effects of Atomic Radiation, 1988 Report to the General Assembly, With Annexes. New York: United Nations.

Urquhart JD, Black RJ, Muirhead MJ, Sharp L, Maxwell M, Eden OB, Adams Jones D (1991): Case-control study of leukaemia and non-Hodgkin's lymphoma in children in Caithness near the Dounreay nuclear installation. Br Med J 302:687-692.

Wakeford R, Wilkie D (1989): Childhood leukaemia and nuclear installations. J R Stat Soc A152:61-86.

Wakeford R, Tawn EJ, McElvenny DM, Scott LE, Binks K, Parker L, Dickinson H, Smith J (1994): The descriptive statistics and health implications of occupational radiation doses received by men at the Sellafield nuclear installation before the conception of their children. J Radiol Prot (in press).

Whittemore AS, Friend N, Brown BW, Holly EA (1987): A test to detect clusters of disease. Biometrika 74:631-637.

Yoshimoto Y, Neel JV, Schull WJ, Kato H, Soda M, Eto R, Mabuchi K (1990): Malignant tumors during the first 2 decades of life in the offspring of atomic bomb survivors. Am J Hum Genet 46:1041-1052.

Yoshimoto Y, Schull WJ, Kato H, Neel JV (1991): "Mortality Among the Offspring $\left(F_{1}\right)$ of Atomic Bomb Survivors, 1946-85. TR 1-91. Hiroshima: Radiation Effects Research Foundation.

Zuelzer WW, Cox DE (1969): Genetic aspects of leukemia. Semin Hematol 6:228-249. 